\title{
Nota Sobre o Frege de Evans
}

Sagid Salles ${ }^{1}$

1 Graduado em filosofia pela Universidade Federal de Ouro Preto, Mestre e Doutor em Filosofia pelo Programa de Pós-Graduação Lógica e Metafísica da Universidade Federal do Rio de Janeiro. Realizou o período sanduíche de seu doutorado na Universidade de Miami.

E-mail: sagidsalles@gmail.com

RESUMO: Evans famosamente declarou que Frege não aceitou a possibilidade de sentido sem referente, o que significa que ele não foi tão tolerante com nomes vazios quanto comumente se pensa. Um problema central para a tese de Evans é que Frege diz explicitamente que aceita esta possibilidade, e parece que ele de fato foi tolerante com nomes vazios. Neste artigo, defendo que a solução de Evans para este problema implica que Frege estava comprometido com uma explicação implausível das frases contendo nomes vaziOs.

Palavras-chave: Frege. Evans. Nomes vazios. Sentido sem referente.

ABSTRACT: Evans has famously claimed that Frege did not accept the possibility of sense without referent, which means that he was not as tolerant with empty names as it has been usually thought. A central problem for Evans's claim is that Frege explicitly says that he accepts this possibility, and it seems that he indeed was tolerant with empty names. In this paper, I defend that Evans's solution to this problem entails that Frege was committed to an implausible account of sentences containing empty names.

Keywords: Frege. Evans. Empty names. Sense without referent.

\section{Introdução}

Dentre muitas outras coisas, a teoria fregeana do sentido e referência tornou-se famosa por sua aparente habilidade de lidar com puzzles envolvendo nomes vazios. Esta habilidade se deve ao fato de ela poder atribuir um sentido a um nome que não possui qualquer referente. Tenha ou não a teoria de Frege a capacidade de lidar com estes puzqles, uma coisa é certa: foi assim que os filósofos geralmente a tomaram ao longo dos anos.1Geralmente, pois houve exceções, e G. Evans foi uma delas. Em The VarietiesofReferen$c e$,Evans argumenta a favor da tese de que, ao contrário do que comumente se pensa, Frege não pôde, e sequer pretendeu, acomodar a possibilidade de sentido sem referente. A interpretação de Evans colide diretamente com trechos nos quais Frege declara explicitamente aceitar esta possibilidade. Neste artigo, defendo que a solução de Evans para o conflito em questão compromete Frege com uma explicação implausível das frases contendo nomes vazios. Minha conclusão é que devemos ver o Frege de Evans com alguma cautela, aceitando apenas em último caso que ele corresponda ao Frege real.

\section{Frege}

Frege começa seu "Sobre o Sentido e a Referência" colocando um enigma envolvendo afir-

${ }^{1}$ Brock (2004) fornece alguns exemplos de como a teoria fregeana - principalmente em interpretações descritivistas - foi geralmente tomada, mesmo pelos seus críticos, como bem-sucedida em resolver problemas envolvendo nomes vazios. Apesar disto, vale notar que o próprio Brock, no mesmo artigo mencionado aqui, coloca em xeque esta aparente habilidade da teoria. 


\section{mações de identidade, que ficou conhecido como puzzle ou quebra-cabeças de Frege. Comece por con- siderar as duas frases a seguir:}

(1) Héspero é Héspero.

(2) Héspero é Eósforo.

(1) é uma identidade trivial que pode ser conhecida a priori, não representando qualquer extensão significativa de nosso conhecimento. Mas (2) pode ser considerada uma grande descoberta científica, e representa uma extensão considerável de nosso conhecimento. De fato, (1) e (2) têm valores cognitivos diferentes, o que significa que um mesmo sujeito pode coerentemente sustentar diferentes atitudes proposicionais com relação a elas. Por exemplo, um mesmo sujeito pode racionalmente acreditar em (1) ao mesmo tempo em que nega (2). Sabendo que os nomes "Héspero" e "Eósforo" se referem ao mesmo objeto, o planeta Vênus, como explicar estas diferenças entre (1) e (2)?

O problema pode ser melhor ilustrado se considerarmos a perspectiva referencialista sobre a contribuição dos nomes próprios para o significado das frases completas que os contêm. De acordo com o referencialismo, a única contribuição de um nome é seu referente; ou seja, a única função semântica de um nome é selecionar um objeto no mundo e introduzi-lo no discurso. Assim, o nome "Héspero" introduz o objeto Héspero em (1) e (2), e "Eósforo” introduz Eósforo em (2). Uma vez que Héspero e Eósforo são o mesmo objeto, seus nomes fazem a mesma contribuição semântica para as frases que os contêm. Se confiarmos no princípio de composicionalidade do significado de frases, que afirma que o significado de uma frase é determinado por sua estrutura e pelo significado das suas partes, concluímos que (1) e (2) significam a mesma coisa. Se isto estivesse correto, contudo, ficaríamos sem uma explicação para o fato de (1), mas não (2), ser uma identidade trivial, e para o fato de (1) e (2) possuírem diferentes valores cognitivos.

Frege pensava que este enigma mostrava a necessidade de uma distinção entre o referente e o sentido de um nome próprio. O referente de um nome próprio é o objeto referido por ele. O sentido seria o modo de apresentação do referente. Cada nome pode possuir tanto um referente como um sentido. Além disto, dois nomes diferentes podem ter o mesmo referente e, contudo, apresentá-lo de modos diferentes. Isto coloca Frege no caminho para uma resposta ao enigma proposto acima. Sem entrar em detalhes, o ponto crucial da solução é o seguinte. Apesar de "Héspero" e "Eósforo" terem o mesmo referente, eles o apresentam de modos diferentes. Por outras palavras, estes nomes têm o mesmo referente, porém não o mesmo sentido. Neste contexto, (1) é uma identidade trivial porque o mesmo objeto é apresentado do mesmo modo duas vezes, enquanto (2) é informativa porque o objeto é apresentado de dois modos diferentes. A explicação da diferença de valor cognitivo destas frases se baseia em que, enquanto a verdade delas depende apenas do referente dos nomes, seu valor cognitivo envolve também o sentido dos mesmos. (Para uma explicação introdutória e muito mais detalhada do enigma e da solução de Frege para o mesmo, veja Li$\mathrm{ma}(2016))$.

Frege não foi totalmente claro quanto ao que exatamente é o sentido ou o modo de apresentação.2 Com alguma segurança, podemos dizer que o sentido de uma expressão é aquilo que o falante compreende quando entende a expressão. Além disto, o sentido pode ser compreendido por todos que estejam sufici-

\footnotetext{
2 Por sua vez, isso dá considerável liberdade aos fregeanos, que podem discordar entre si sobre como entender o sentido, desde que concordem com algumas restrições como (i) o sentido tem de determinar o referente de algum modo, (ii) tem de poder ser compreendido por todos que dominam a linguagem, etc. Quanto a quem é o fregeano, e quais requisitos mínimos alguém tem de satisfazer para ser um fregeano, ver Schiffer (2000, p. 6).
} 
entemente familiarizados com a linguagem; ou seja, o sentido é objetivo e não privado. Quanto à relação entre um nome, o sentido de um nome, e seu referente, os seguintes pontos são importantes: (i) um nome pode ser associado a pelo menos um sentido determinado; (ii) a um sentido corresponde, no máximo, um único referente; (iii) a um referente podem corresponder diferentes expressões com diferentes sentidos.

É importante ressaltar que, apesar de até agora ter falado da distinção fregeana apenas no que diz respeito a nomes próprios, Frege estendeu-a a todas as expressões da linguagem, incluindo frases completas. Assim, uma frase pode ter tanto um sentido como um referente. Ao sentido de uma frase Frege chamou o pensamento expresso por ela. Seu referente seria seu valor de verdade: o Verdadeiro ou o Falso. Isto é o bastante para prosseguirmos.

\section{Evans}

Intuitivamente, ambas as frases abaixo expressam um pensamento.

(3) Vulcano é um planeta.

(4) Sherlock Holmes é um detetive.

Entretanto, o referencialismo tem um problema com frases desse tipo. Uma vez que "Vulcano" e "Sherlock Holmes" não possuem qualquer referente, também não possuem, de acordo com esta perspectiva, qualquer significado. Mas o principio da composicionalidade mencionado acima parece implicar que se uma parte da frase não tem significado, então a frase toda não tem. Assim, (3) e (4) não expressam qualquer pensamento. Esta conclusão é altamente contraintuitiva. Frege, por outro lado, não teria problemas com frases que contêm nomes vazios. De tudo que dissemos até agora, nada nos impede de aceitar que um nome próprio possa ter um sentido e não ter um referente. Dado que o sentido de uma frase é composto do sentido de suas partes, podemos aceitar que (3) e (4) expressem cada uma um pensamento.

Evans, no entanto, discordou da interpretação acima. Em The VarietiesofReference ele apresenta alguns argumentos diferentes contra a ideia de que Frege realmente tenha sido tão tolerante quanto à possibilidade de sentido sem referente. Cada um dos argumentos aponta para uma inconsistência entre a tese da possibilidade de sentido sem referente e alguma outra tese ou ponto avançado por Frege. Seu principal argumento, o único que será considerado aqui, é indicado na seguinte passagem.

Here it seems to me that we finally come to the great fault-line in Frege's mature philosophy of language. What can it mean on Frege's, or on anyone's, principles, for there to be a perfectly determinate thought which simply has no truth-value? (EVANS, 1982, p. 24)

Frege sustentou o princípio de composicionalidade não apenas para o significado, mas também para o referente das frases. Deste modo, o referente de uma frase é determinado pelos referentes de suas partes. Novamente, daí decorre que se uma parte qualquer não tem referente, então a frase completa também não tem. Uma vez que o referente de uma frase é seu valor de verdade (o Verdadeiro ou o Falso), a frase em questão seria destituída de valor de verdade. Portanto, (3) e (4) seriam nem verdadeiras nem falsas. O problema é que é difícil entender como (3) e (4) poderiam expressar um pensamento (ter um sentido) sem valor de verdade. Pensamentos sem valor de verdade simplesmente não são pensamentos. Se isto está correto, então Frege não pode realmente aceitar que tais frases expressem um pensamento e, conse- 
quentemente, não pode realmente aceitar a possibilidade de sentido sem referente. A conclusão mais geral é que a possibilidade de um sentido sem referente seria inconsistente com a tese de Frege de que frases contendo nomes vazios não possuem um valor de verdade.

O que há de tão problemático em Frege aceitar a possibilidade de pensamentos sem valor de verdade? A continuação do trecho citado acima revela uma das respostas de Evans a isto.

Remember that the notion of thought that Frege was intending to use had strong links with notions embedded in ordinary propositional-attitude psychology - the notions of belief, knowledge, memory, information, judgment, and so on. If someone understands and accepts a sentence containing an empty name, then, according to Frege, he thereby forms a belief; not a belief about language, but a belief about the world. But what sense can be made of a belief which literally has no truth-value-which is neither correct nor incorrect? (EVANS, 1982, p. 24)

Neste trecho, Evans chama a atenção para o fato de que o conceito fregeano de pensamento está conectado à ideia de atitude proposicional. Como vimos, a tese de Frege de que frases como (1) e (2) expressam pensamentos diferentes baseou-se no fato de que um mesmo sujeito pode ter diferentes atitudes proposicionais com relação a elas. De acordo com Frege, uma condição suficiente para p e q serem pensamentos diferentes é que um sujeito possa coerentemente sustentar diferentes atitudes proposicionais com relação a eles. Analogamente, uma condição necessária para p e q serem o mesmo pensamento é que nenhum sujeito possa coerentemente sustentar diferentes atitudes proposicionais com relação a eles. Na verdade, pensamentos são objetos de atitudes proposicionais. O pensamento de que p é o objeto de sua crença quando você acredita que p, e sua crença é dita verdadeira/falsa precisamente quando o pensamento que é seu objeto é verdadeiro/falso. Neste contexto, a crença de que Vulcano é um planeta teria o mesmo valor de verdade que o pensamento de que Vulcano é um planeta. Dado que o último seria destituído de valor de verdade, a primeira também seria. Mas Evans pensa que faz pouco sentido falar em uma crença sendo nem verdadeira nem falsa.

Indo na mesma direção de Evans, McDowell (2005, p. 60) observa que uma frase que expressa um pensamento pode ou não ter sucesso em dizer que algo é o caso. Se ela tem sucesso, então o pensamento expresso por ela é verdadeiro. Se falha, então o pensamento é falso. Mas quando é que ela falharia em ter um valor de verdade qualquer? Não é claro como isto poderia acontecer.

Apesar de hesitar sobre a plausibilidade destes ou dos outros argumentos de Evans, não vou disputá-los aqui. Ao contrário, vou simplesmente conceder que haja uma incompatibilidade entre a possibilidade de sentido sem referente e a ideia de que frases contendo nomes vazios são destituídas de valor de verdade. Podemos, a partir disto, sustentar que Frege rejeitou a possibilidade de sentido sem referente? A resposta mais imediata é "não". Pois, como o próprio Evans reconhece, Frege de fato parece ter aceitado esta possibilidade. Os seguintes trechos de "Sobre o Sentido e a Referência" não me deixam mentir.

As palavras "o corpo celeste mais distante da terra" têm um sentido, mas é muito duvidoso que também tenham uma referência. (FREGE, 1892, p. 63)

A Sentença "Ulisses profundamente adormecido foi desembarcado em Ítaca" tem, obviamente, um sentido. Mas, assim como é duvidoso que o nome "Ulisses", que aí ocorre, tenha uma referência, é também duvidoso que a sentença inteira tenha uma. (...) O pensamento permanece o mesmo se o nome Ulisses tem referência ou não. (FREGE, 1892, p. 68). 
No segundo trecho citado, Frege não apenas assume a possibilidade de sentido sem referente, ele alega que é óbvio que a frase em questão contendo um nome vazio tem um sentido. Trechos como estes conflitam diretamente com a interpretação proposta por Evans.

Além disto, Frege intencionalmente apela à possibilidade de sentido sem referente como uma de suas premissas a favor da tese de que pelo menos algumas frases têm um referente. Utilizando, com algumas modificações, a formulação de Kremer (2010, p. 264), o argumento de Frege é como segue.

(A) Em alguns casos (como aqueles envolvendo Ulisses citado acima, poesia, ficção, etc.) o sentido da frase permanece o mesmo, tendo ou não uma parte da frase um referente. Nesses casos, tão logo uma parte da frase falhe em ter um referente, a frase como um todo também falha em ter um referente.

(B) Nesses casos, contudo, estamos preocupados apenas com o sentido das frases e de suas expressões componentes, e não com seu referente.

(C) Mas há outros casos; aqueles em que estamos preocupados com a busca da verdade; em que os referentes das partes componentes das frases importam.

(D) Assim, deve existir alguma característica das frases tal que (i) dependa dos referentes de suas partes, e (ii) esteja de acordo com o nosso interesse pela referência das partes em contextos de procura pela verdade.

(E) Essa característica pode ser chamada de o referente das frases.

Ao esboçar a distinção entre ficção ou poesia e os contextos nos quais a procura pela verdade importa, Frege apela à possibilidade de sentido sem referente. É com base nisto que ele então conclui que o segundo caso é especial no sentido de exigir um referente para as frases envolvidas.

Em resumo, mesmo que Evans esteja certo sobre o fato de que Frege não poderia ter coerentemente aceitado a possibilidade de sentido sem referente, o fato é que Frege parece mesmo ter aceitado esta possibilidade. Na próxima seção, discuto como Evans lida com este problema, e sustento que sua solução acaba atribuindo a Frege uma explicação implausível das frases contendo nomes vazios.

\section{A solução de Evans}

O contraste supramencionado entre poesia ou ficção e os contextos nos quais a verdade importa têm alguma importância para a solução de Evans. Sua solução pode ser apresentada em três passos. Primeiro, Frege reconheceu que contextos ficcionais envolvem aspectos diferentes daqueles envolvidos em usos sérios da linguagem. Estes aspectos fazem com que o discurso ficcional mereça um tratamento especial e diferente daquele fornecido por Frege para a linguagem em geral. Segundo, apesar de Frege não ter fornecido qualquer teoria sistemática do discurso ficcional, ele teria sugerido que frases envolvendo nomes vazios não exprimem realmente pensamentos em tais contextos, mas pensamentos simulados ou meramente aparentes. Terceiro, Frege teria assimilado frases contendo nomes vazios em contextos não ficcionais com aquelas ocorrendo em contextos ficcionais, de modo que as primeiras também falhariam em expressar um pensamento real, e no máximo poderiam ter sucesso em expressar um pensamento simulado ou meramente aparente. Com isto em mente, as aparentes inconsistências podem ser desfeitas se interpretarmos os trechos em que Frege explicitamente aceita a possibilidade de sentido sem referente como trechos que Frege estaria disposto a qualificar do seguinte modo: É verdade que frases contendo nomes vazi- 
os podem expressar um pensamento no sentido em que elas não são mero ruído ou absurdas, mas estes pensamentos são pensamentos meramente simulados ou aparentes, e não pensamentos reais. Se lermos os trechos de Frege sob esta qualificação, as incoerências mencionadas na seção anterior desaparecem. Aqui estão os trechos nos quais Evans apresenta sua solução.

Frege assimilated perfectly serious uses of empty definite descriptions ('the least rapidly convergent series') and empty demonstratives ('that lime tree') to fictional uses of language. (EVANS, 1982, p. 28).

The unqualified passages ascribing sense to empty singular terms and sentences containing them do induce an inconsistency. But when they are interpreted in the light of Frege's views on fiction the inconsistency disappears, for we may gloss those passages in which Frege says that a sentence containing an empty singular term may express a thought as follows. Yes: a sentence containing an empty singular term may have a sense, in that it does not necessarily have to be likened to a sentence containing a nonsense-word. But no: it does not really have a sense of the kind possessed by ordinary atomic sentences, because it does not function properly, it is only as if it functions properly. Frege's use of the notion of fiction wrongly directs our attention to just one case in which it is as if a singular term refers to something, namely when we are engaged in a pretence that it does, but there are others, and if we think of them, we might speak of apparent, rather than mock or pretend, thoughts. (EVANS, 1982, p. 30).

Uma defesa adequada desta interpretação depende de indícios a favor das duas seguintes teses: (i) Frege defendeu um tratamento especial do tipo mencionado acima para as frases contendo nomes vazios em contextos ficcionais, e (ii) Frege realmente assimilou o tratamento das frases contendo nomes vazios em contextos não ficcionais com o daquelas ocorrendo em contextos ficcionais. Evans de fato apresenta alguns trechos que serviriam de indício para cada uma destas teses, mas vou deixar isto de lado aqui. Limito-me a ressaltar um difícil dilema que o Frege de Evans teria de enfrentar. O dilema pode ser colocado no argumento abaixo.

1. De acordo com Evans, Frege teria reconhecido casos envolvendo nomes vazios em discursos ficcionais como envolvendo algum tipo de simulação ou faz de conta.

2. Agora, ou Frege tratou discursos envolvendo nomes vazios em contextos não ficcionais como também envolvendo algum tipo de simulação ou faz de conta, ou não o fez.

3. Se ele fez isto, então sua explicação falha por carregar o problema da motivação semântica. Se ele não fez, então sua explicação do discurso não ficcional envolvendo nomes vazios não passa de uma suposição arbitrária.

4. Em qualquer caso, a explicação do Frege de Evans falha.

Vejamos premissa por premissa do argumento acima. A premissa (A) se refere ao fato de o Frege de Evans ter antecipado o tipo de explicação do discurso ficcional posteriormente esboçado por John Searle (1979) e detalhadamente desenvolvido por Kendall Walton (1990). De acordo com este tipo de explicação, uma pessoa que diz algo como "Sherlock Holmes é um detetive" em um contexto ficcional não está a fazer uma afirmação séria. Ao contrário, está simulando fazer uma afirmação. Esta simulação envolve dois passos. Primeiro, a pessoa simula usar o nome "Sherlock Holmes" referencialmente, ela faz, de conta que está se referindo a algo por meio deste nome. Segundo, ela simula atribuir uma propriedade ao referente (simulado) do nome, ela faz de conta que está atribuindo a propriedade de ser um detetive a ele. Este tipo de explicação do discurso ficcional tem se mostrado promissor, e seria um mérito de Frege se ele o tivesse 
antecipado.

Como bem sabemos, nem todo uso de nomes vazios ocorre em contextos ficcionais. Um exemplo disto é o nome "Vulcano". Este nome foi usado de forma séria por cientistas do século XIX para fazer referência a um planeta que eles então pensavam existir, mas que posteriormente descobriu-se que não existia. A história da postulação e refutação da existência deste planeta é belamente contada em Levenson (2015). A premissa (B) é bastante direta, ou o Frege de Evans interpretou estes casos de usos aparentemente sérios como meras simulações ou faz de conta, ou o Frege de Evans os tratou como casos diferentes.

Isto nos leva diretamente à premissa (C). Suponha que o Frege de Evans tenha interpretado os casos envolvendo nomes vazios em contextos não ficcionais como casos envolvendo simulação ou faz de conta. Esta é uma tese sobre o modo como falantes reais estão usando nomes vazios em certos contextos. Por exemplo, de acordo com esta explicação, os cientistas que ao longo de muitas décadas usaram o nome "Vulcano" não estavam a usá-lo seriamente para fazer referência a Vulcano, mas apenas simulando ou fazendo de conta que estavam a se referir a algo através deste nome. Esta tese contraria fortemente nossas intuições, uma vez que não parece que tais cientistas estavam engajados em qualquer jogo de faz de conta ou simulação. Ao contrário, parece que estavam a falar muito seriamente. Isto levanta o que chamei de o "problema da motivação semântica": "o problema de motivar a afirmação de que falantes estão engajados em um jogo de faz de conta ou alguma espécie de atividade de simulação quando a intuição é que eles não estejam" (SALLES, 2015, p. 190-191). Sem uma solução para o problema da motivação semântica, a tese acima dificilmente pode ser considerada uma alternativa viável.

Mas então suponha que o Frege de Evans não tenha interpretado nomes vazios ocorrendo em contextos não ficcionais como envolvendo alguma simulação ou faz de conta. Aliás, esta parece ser a sugestão de Evans no segundo trecho citado acima. Se este for o caso, o Frege de Evans escapa do problema da motivação semântica, na medida em que ele não precisa mais sustentar que certos usos aparentemente sérios da linguagem são na verdade casos envolvendo simulação ou faz de conta. Ao contrário, os usos de frases contendo nomes vazios em contextos não ficcionais são perfeitamente sérios, embora ainda assim falhem em expressar um pensamento genuíno. Mas agora o Frege de Evans se depara com um novo problema: o que explica a nossa forte intuição de que frases contendo nomes vazios ocorrendo em contextos não ficcionais podem expressar pensamentos genuínos? Por exemplo, é inegavelmente intuitivo que os cientistas do século XIX estavam a expressar pensamentos genuínos por meio de frases como "Vulcano é um planeta". Apesar de carecer de motivação semântica, a perspectiva anterior nos fornece um modo de explicar a intuição em causa. A razão de "Vulcano é um planeta" parecer expressar um pensamento é que as pessoas, ao proferirem esta frase, estão agindo como se ela expressasse um pensamento. Nosso engajamento nesta prática de simular ou fazer de conta que estamos a expressar um pensamento acaba gerando a equivocada aparência de que estamos de fato expressando um pensamento. Tão logo o Frege de Evans abandona o conceito de simulação ou far de conta, no entanto, esta explicação já não está mais disponível. Por outras palavras, o Frege de Evans está declarando que certos proferimentos cotidianos que parecem expressar um pensamento não expressam realmente um pensamento, mas não nos fornece, em contrapartida, qualquer explicação para nossa forte intuição contrária. Neste caso, a tese do Frege de Evans de que frases contendo nomes vazios em contextos não ficcionais falham em expressar um pensamento genuíno carece de justificativa, e sua explicação como um todo se torna implausível.

Por fim, (D) é a conclusão do argumento, e se segue logicamente das premissas (A)-(C). Resumindo, ou a explicação do Frege de Evans carece de motivação semântica ou depende de uma suposição arbitrária. Em ambos os casos, ela será implausível. Portanto, a explicação do Frege de Evans é implausível. 
Nada disto implica que a controversa interpretação de Frege proposta por Evans está errada. No fim das contas, é possível que Frege tenha recorrido a uma explicação implausível do discurso envolvendo nomes vazios, a fim de conciliar suas declarações sobre a possibilidade de sentido sem referente com outras teses aparentemente inconsistentes com a última. Mas esta é uma possibilidade que devemos ver com cautela. Para evitar certas inconsistências entre supostas teses de Frege, Evans gera o custo de rejeitar afirmações explícitas de Frege acerca da possibilidade de sentido sem referente, e atribui a este uma explicação implausível do discurso envolvendo nomes vazios. Não está claro se o custo desta interpretação supera os benefícios da mesma. Mesmo que supere, provavelmente devemos ver a interpretação de Evans como um último recurso, algo que devemos aceitar apenas se não tivermos outros modos de evitar as inconsistências apontadas por ele.

\section{Referências}

BROCK, Stuart (2004). The Ubiquitous Problem of Empty Names. The Journal of Philosophy, v. 101, n. 6, pp. 277-298.

EVANS, Gareth (1982). The Varieties of Reference. Oxford: Oxford University Press.

FREGE, Gottlob (1892). Sobre o Sentido e a referência. In: Lógica e Filosofia da Linguagem. São Paulo: Cultrix, 1978. Tradução de Paulo Alcoforado.

KREMER, M. (2010). Sense and Reference: the origins and development of the distinction. In: POTTER, M.; RICKETTS, T. (orgs). The Camridge Companion to Frege. Cambridge University Press, pp.220-292.

LEVENSON, Thomas (2015). The Hunt for Vulcan. New York: Randon House.

LIMA, Juliana F. (2016). O Enígma de Frege. Fundamento, n. 12.

MCDOWELL, John (2005). Evans's Frege. In: BERMUDEZ, J. L. Thought, Reference, and Experience: Themes from the philosophy of Gareth Evans. Clarendon Press.

SALLES, Sagid (2015). Fazendo de Conta que Vulcano não Existe. Philósophos, v. 20, n. 2, pp. 171-196.

SCHIFFER, Stephen (2000). Peonastic Fregeanism and Empty Names. In: EVERETT, A.; HOFWEBER, T. (orgs). Empty Names, Fiction, and the Puzzles of Non-Existence. CSLI publications.

SEARLE, John R. (1979). O Estatuto Lógico do Discurso Ficcional. In: Expressão e Significado. Martins Fontes, 1995. Tradução de Ana Cecília G. A. de Camargo e Ana Luiza Marcondes Garcia.

WALTON, Kendall L. (1990). Mimesis as Make-Believe. Cambridge: Harvard University Press.

Artigo recebido em: 26 de dezembro de 2019

Artigo aceito em: 26 de dezembro de 2019 